\title{
Пассивация поверхности GaAs нитевидных нанокристаллов с помощью молекулярного наслаивания AIN
}

\author{
(С) И.В. Штром ${ }^{*+\bullet}$, А.Д. Буравлев ${ }^{*+\bullet}$, Ю.Б. Самсоненко ${ }^{+\bullet}$, А.И. Хребтов ${ }^{+}$, И.П. Сошников ${ }^{*+\bullet}$, \\ P.P. Резник ${ }^{\ddagger}$, Г.Э. Цырлин ${ }^{+\bullet}$, V. Dhaka`, A. Perros`, H. Lipsanen" \\ * Физико-технический институт им. А.Ф. Иоффе Российской академии наук, \\ 194021 Санкт-Петербург, Россия \\ + Санкт-Петербургский академический университет Российской академии наук, \\ 194021 Санкт-Петербург, Россия \\ - Институт аналитического приборостроения Российской академии наук, \\ 190103 Санкт-Петербург, Россия \\ - Санкт-Петербургский национальный исследовательский университет \\ информационных технологии, механики и оптики (Университет ИТМО), \\ 197101 Санкт-Петербург, Россия \\ - Aalto University, Fl-00076 Espoo, Finland \\ ‡ Санкт-Петербургский политехнический университет Петра Великого, \\ 195251 Санкт-Петербург, Россия \\ E-mail: igorstrohm@mail.ru; cirlin@beam.ioffe.ru
}

(Получена 27 апреля 2016 г. Принята к печати 10 мая 2016 г.)

Продемонстрировано, что молекулярное наслаивание тонких слоев AlN может быть использовано для пассивации поверхностных состояний GaAs нитевидных нанокристаллов, синтезированных с помощью молекулярно-пучковой эпитаксии. Исследование оптических свойств образцов методом низкотемпературной фотолюминесценции показало, что интенсивность сигнала фотолюминесценции может быть увеличена вплоть до 5 раз при пассивации нитевидных нанокристаллов слоем AlN с толщиной $25 \AA$.

\section{1. Введение}

Нитевидные нанокристаллы (ННК) на основе $\mathrm{A}^{\mathrm{III}} \mathrm{B}^{\mathrm{V}}$ полупроводниковых соединений обладают целым рядом уникальных свойств, которые позволяют их рассматривать в качестве перспективных материалов для создания новых приборов нано- и оптоэлектроники. Одна из характерных особенностей не только $\mathrm{A}^{\mathrm{III}} \mathrm{B}^{\mathrm{V}}$, но и всех остальных нитевидных нанокристаллов, заключается в высоком аспектном соотношении их поверхностной площади к их объему. Большая площадь поверхности ННК может приводить к целому ряду как положительных, так и отрицательных свойств. Так, например, создание коаксиальных ННК позволяет получить большую площадь $p-n$-перехода и, как следствие, повысить эффективность солнечных элементов на их основе. С другой стороны, в первую очередь для ННК на основе $\mathrm{A}^{\mathrm{III}} \mathrm{B}^{\mathrm{V}}$ соединений (например, GaAs) бо́льшая площадь поверхности может приводить к образованию большого числа поверхностных состояний. Аналогично случаю объемных материалов, их наличие может приводить к пинингу уровня Ферми [1,2], что может отрицательно сказываться на работе приборов на основе ННК вследствие их небольших диаметров, соотносящихся с шириной создаваемых приповерхностных обедненных слоев. Для решения этой проблемы, как и в случае объемных полупроводников, особое внимание уделяется различным способам пассивации поверхности [3-6].

На сегодняшний день одним из основных широко используемых способов для пассивации поверхности ННК является формирование оболочки из более широкозонного материала. В случае пассивации $\mathrm{GaAs}$ HНK чаще всего создают внешнюю оболочку на основе по- лупроводниковых соединений $\mathrm{Al}_{x} \mathrm{Ga}_{1-x} \mathrm{As}$ [7-9]. Однако подобные соединения, хоть и обладают большим значением ширины запрещенной зоны, но не столь значительным. Таким образом, формирование пассивирующих слоев для GaAs HНK на их основе не всегда может быть выгодно с точки зрения исследования, например, оптических свойств ННК.

Поэтому в настоящее время пристальное внимание уделяется также и другим способам пассивации поверхности ННК. Так, например, недавно был продемонстрирован способ химической нитридизации поверхности GaAa ННК [3]. Тем не менее, на наш взгляд, одним из наиболее перспективных способов пассивации поверхности является использование метода молекулярного наслаивания (MH) [4]. Хорошо известно, что метод МН может быть использован для нанесения абсолютно беспористых и равномерных покрытия с прецизионной точностью по толщине на подложки сложной формы и геометрии. Поэтому использование данного метода для пассивации поверхности образцов с выращенными ННК имеет широкие перспективы, поскольку осаждаемый пассивирующий слой должен обладать большой равномерностью.

Настоящая работа посвящена исследованию влияния AlN пассивации поверхности GaAs HНK, синтезированных с помощью молекулярно-пучковой эпитаксии, на их оптические свойства.

\section{2. Экспериментальные методы}

Ростовые эксперименты проводились на установке молекулярно-пучковой эпитаксии (МПЭ) Compact21 
фирмы Riber, оснащенной эффузионными источниками галлия и мышьяка. В качестве подложек использовались полированные полуизолирующие пластины кремния с ориентацией поверхности типа (111). Синтез ННК происходил по стандартному механизму „паржидкость-кристалл“. Более подробное описание ростовых процессов приведено, например, в [10]. Однако для достижения большей однородности массива GaAs ННК по размерам в качестве катализатора роста ННК использовались коллоидные наночастицы золота. Рост производился при температуре $550^{\circ} \mathrm{C}$ в течение 30 мин. Для исследования поверхности во время проведения ростовых экспериментов in situ, использовался метод дифракции быстрых электронов на отражение (ДБЭО), который показал присутствие как кубической, так и вюрцитной фазы в GaAs HНК. Исследование поверхностной морфологии полученных образцов проводилось методом растровой электронной микроскопии (РЭМ) на микроскопе Supra25 фирмы Zeiss.

Для осаждения слоев AIN на поверхность МПЭ синтезированных GaAs HНК использовался метод молекулярного наслаивания стимулированного плазмой [4]. Эксперименты были проведены на установке MHTFS500 фирмы Beneq. Слои AlN осаждались при температуpe $200^{\circ} \mathrm{C}$, с использованием прекурсоров триметилалюминия (ТМА) и $\mathrm{NH}_{3}$. В качестве газа-носителя выступал азот. Эквивалентная толщина осаждаемых слоев AlN составила 5 и $25 \AA$ соответственно.

Оптические свойства полученных массивов ННК исследовались с помощью метода низкотемпературной фотолюминесценции (ФЛ). Измерения проводились на специальном оптическом стенде, включающем дисперсионный спектрометр, собранный на базе монохроматора МДР-204-2 фирмы „ЛОМО Фотоника“. ФЛ возбуждалась непрерывным лазером с длиной волны возбуждения 532 нм. Плотность мощности возбуждения составляла около $10 \mathrm{~B}$ / $/ \mathrm{cm}^{2}$. В качестве фотоприемника использовался фотоэлектронный умножитель Hamamatsu R928. Возбуждение и детектирование сигнала ФЛ проводились в нормальной геометрии. Измерения проводились при температуре $15 \mathrm{~K}$, для их проведения образцы с ННК помещались в гелиевый криостат замкнутого цикла.

\section{3. Результаты и обсуждение}

Результаты исследования морфологических свойств образцов, проведенного с помощью РЭМ представлено на рис. 1. Видно, что синтезированные массивы GaAs ННК обладают небольшим разбросом параметров. Высота ННК составляет порядка 11 мкм (см. рис. 1, $a$ ), а их диаметр около 120 нм (см. рис. $2, b)$. Поскольку для синтеза были использованы подложки $\mathrm{Si}(111)$, подавляющее число ННК оказалось ориентировано перпендикулярно поверхности, т. е. рост происходил вдоль кристаллографических направлений типа $\langle 111\rangle$. Следует еще раз особо подчеркнуть, что полученные массивы $\mathrm{GaAs}$ ННК обладали незначительным разбросом параметров. Это позволило исследовать практически одни и те же
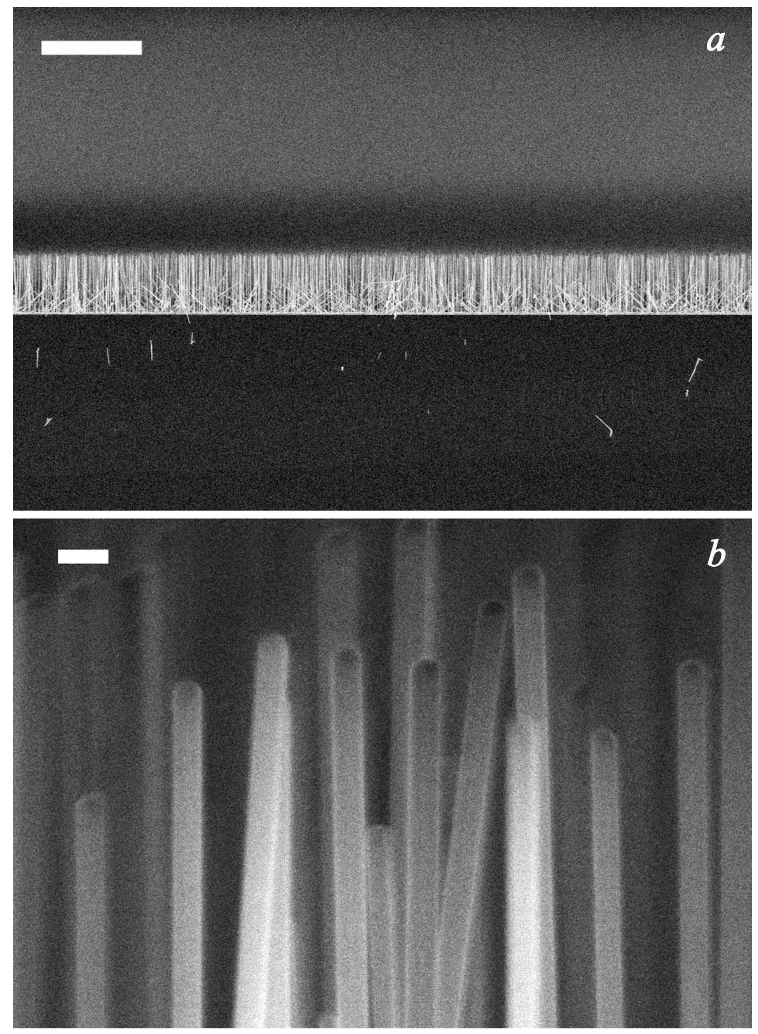

Рис. 1. РЭМ изображения синтезированных массивов GaAs ННК. Масштабная метка соответствует: $a-20$ мкм, $b-200 \mathrm{Hм}$.

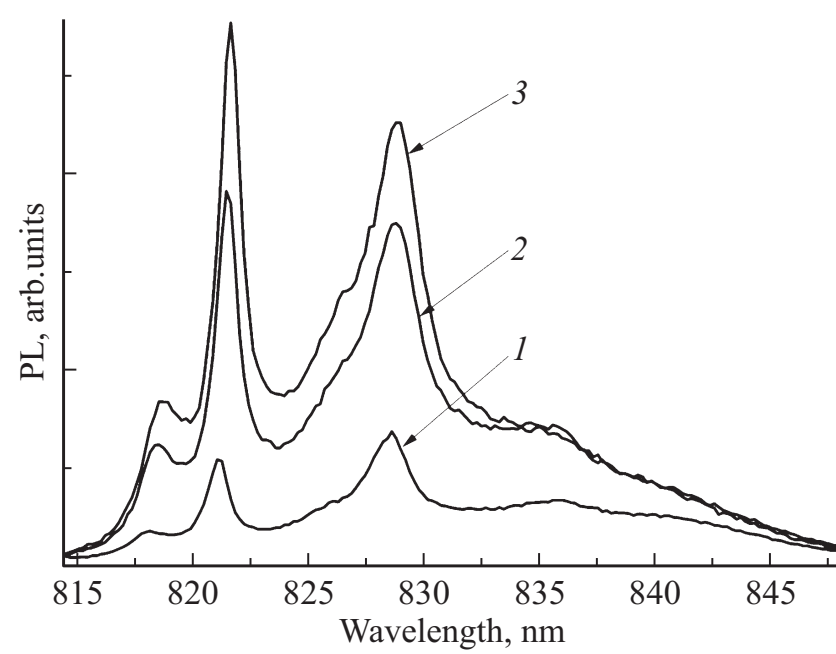

Рис. 2. Спектры ФЛ от массивов GaAs ННК: 1 - без пассивации, 2 - после пассивации слоем AlN с эквивалентной толщиной $5 \AA$, 3 - после пассивации слоем AlN с эквивалентной толщиной $25 \AA$.

GaAs HНК, синтезированные в одинаковых условиях, несмотря на то что образцы раскалывались для последующего проведения MH слоев AlN. Поэтому результаты последующих оптических измерений обладают большой достоверностью. 
Как уже было отмечено выше, метод МН был использован для осаждения AlN с толщиной слоев 5 и $25 \AA$ соответственно на поверхность синтезированных GaAs ННК. Далее были исследованы оптические свойства всех образцов как пассивированных, так и непассивированных. Результаты измерений представлены на рис. 2.

Видно, что полученные ФЛ спектры непассивированных GaAs HНК (см. рис. 2, кривая 1) содержат полосу с максимумом в 818 нм, которая соответствует прямому экситонному переходу в GaAs HНК с кубической кристаллической структурой [11]. Кроме того, было обнаружено, что в спектре присутствуют полосы с максимумами в 821 и 830 нм, которые могут быть связаны с присутствием как вюрцитной фазы, так и неконтролируемой примеси в ННК $[7,11]$. Также в длинноволновой части спектров ФЛ присутствует добавочная полоса с максимумом в 835 нм. По нашему мнению, она может быть обусловлена излучением донорно-акцепторных пар в GaAs HНК.

Пассивация поверхности GaAs HНК нитридом алюминия привела к значительному усилению интенсивности сигнала ФЛ (см. рис. 2, кривые 2 и 3). При этом она увеличилась в 3.5 раза (рис. 2, кривая 2) и 5 раз (рис. 2 , кривая 3) для образцов с GaAs HНК пассивированными слоями AlN толщиной 5 и $25 \AA$ соответственно, по сравнению с интенсивностью ФЛ, полученной для непассивированных образцов (рис. 2, кривая 1). Следует отметить, что спектры ФЛ пассивированных ННК содержат полосы ФЛ с теми же максимумами, которые были обнаружены и описаны выше при исследовании непассивированных GaAs HНК (см. рис. 2). Таким образом, пассивация GaAs HНК слоями $\mathrm{AlN}$, осажденных с помощью МН, не привела к сдвигу полос ФЛ.

Возрастание сигнала ФЛ, по-видимому, взаимосвязано с пассивацией поверхностных состояний. Подобный эффект уже наблюдался ранее в работах $[3,4]$. Однако, в отличие от работы [4], мы не обнаружили деградации интенсивности ФЛ при увеличении пассивирующего слоя. Так же как и в работе [4], для объяснения наблюдаемого эффекта требуется проведение дополнительных исследований. Тем не менее, вероятнее всего, это может быть связано с различным уровнем неконтролируемого легирования, в первую очередь углеродом, GaAs HНК, синтезированных методом МПЭ и газофазной эпитаксии из металлорганических соединений (ГФЭМО). Хорошо известно, что в случае синтеза с помощью ГФЭМО уровень неконтролируемого легирования значительно выше.

\section{4. Заключение}

Таким образом, нами было продемонстрировано, что метод МН может быть использован для эффективной пассивации поверхностных состояний GaAs HНК, выращенных методом МПЭ. МН слоев AlN толщиной 5 и $25 \AA$ на поверхность GaAs HНК показало увеличение интенсивности сигнала ФЛ в 3.5 и 5 раз соответственно.

Данная работа выполнена при финансовой поддержке гранта РНФ № 14-12-00393.

\section{Список литературы}

[1] В.Н. Бессолов, М.В. Лебедев. ФТП, 32, 1281 (1998).

[2] Б.И. Бедный. СОЖ, 7, 114 (1998).

[3] V. Dhaka, A. Perros, S. Naureen, N. Shahid, H. Jiang, J.-P. Kakko, T. Haggren, E. Kauppinen, A. Srinivasan, H. Lipsanen. AIP Advances, 6, 015016 (2016).

[4] P.A. Alekseev, M.S. Dunaevskiy, V.P. Ulin, T.V. Lvova, D.O. Filatov, A.V. Nezhdanov, A.I. Mashin, V.L. Berkovits. Nano Lett., 15, 63 (2015).

[5] N. Tajik, C.M. Haapamaki, R.R. LaPierre. Nanotechnology, 23, 315703 (2012).

[6] M. Mattila, T. Hakkarainen, H. Lipsanen, H. Jiang, E.I. Kauppinen. Appl. Phys. Lett., 90, 033101 (2007).

[7] A.V. Senichev, V.G. Talalaev, I.V. Shtrom, H. Blumtritt, G.E. Cirlin, J. Schilling, Ch.P. Werner. ACS Photonics, 1 (11), 1099 (2014).

[8] L.V. Titova, Th.B. Hoang, H.E. Jackson, L.M. Smith, J.M. Yarrison-Rice, H.J. Joyce, H.H. Tan, C. Jagadish. Appl. Phys. Lett., 89, 173126 (2006).

[9] V. Dhaka, J. Oksanen, H. Jiang, T. Haggren, A. Nykänen, R. Sanatinia, J.-P. Kakko, T. Huhtio, M. Mattila, J. Ruokolainen, S. Anand, E. Kauppinen, H. Lipsanen. Nano Lett., 13, 3581 (2013).

[10] G.E. Cirlin, V.G. Dubrovskii, I.P. Soshnikov, N.V. Sibirev, Yu.B. Samsonenko, A.D. Bouravleuv, J.C. Harmand, F. Glas. Phys. Status Solidi RRL, 3, 112 (2009).

[11] V. Novikov, S.Yu. Serov, N.G. Filosofov, I.V. Shtrom, V.G. Talalaev, O.F. Vyvenko, E.V. Ubyivovk, Yu.B. Samsonenko, A.D. Bouravleuv, I.P. Soshnikov, N.V. Sibirev, G.E. Cirlin, V.G. Dubrovskii. Phys. Status Solidi RRL, 4, 175 (2010).

Редактор А.Н. Смирнов

\section{Surface passivation of GaAs nanowires by atomic layer deposition of AIN}

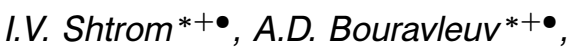 \\ Yu.B. Samsonenko ${ }^{+\bullet \bullet, ~ A . I . ~ K h r e b t o v ~}{ }^{+}$, \\ I.P. Soshnikov ${ }^{*+\bullet, ~ R . R . ~ R e z n i k ~}{ }^{+\ddagger}$, G.E. Cirlin ${ }^{+\bullet}$, \\ V. Dhaka", A. Perros", H. Lipsanen" \\ * Ioffe Institute, \\ 194021 St. Petersburg, Russia \\ + St. Petersburg Academic University, \\ Russian Academy of Sciences, \\ 194021 St. Petersburg, Russia \\ - Institute for Analytical Instrumentation \\ Russian Academy of Sciences, \\ 190103 St. Petersburg, Russia \\ - ITMO University, \\ 197101 St. Petersburg, Russia \\ - Aalto University, \\ FI-00076 Espoo, Finland \\ $\ddagger$ Peter the Great St. Petersburg Polytechnic University, \\ 195251 St. Petersburg, Russia
}

Abstract It is demonstrated that atomic layer deposition of AlN thin layers can be used for the passivation of surface states of GaAs nanowires synthesized by molecular beam epitaxy. Low-temperature photoluminescence investigation shows that the intensity of the photoluminescence signal can be increased up to 5 times for nanowires passivated by AIN thin layer with a thickness of 25 angstroms. 